EPJ Web of Conferences 24, 05008 (2012)

DOI: $10.1051 /$ epjconf/20122405008

(C) Owned by the authors, published by EDP Sciences - SIF, 2012

\title{
A theoretical approach to the re-suspension factor
}

\author{
M. MAGNONI \\ ARPA Piemonte, Dipartimento Tematico Radiazioni \\ Via Jervis 30, 10015 Ivrea (TO), Italy
}

\begin{abstract}
The atmospheric re-suspension of radionuclides is a well-known phenomenon that consists in the re-injection into the atmosphere of previously deposited radioactivity. The process is driven by the action of wind on surfaces and can act as an additional source of radiation exposure by inhalation, after the deposition has finished. It is thus defined as the re-suspension factor, a parameter $K$ generally considered as a time depending function and defined as the ratio of $C_{a}$, the volumetric air activity concentration $\left(\mathrm{Bq} \mathrm{m}^{-3}\right)$ and $I_{0}\left(\mathrm{~Bq} \mathrm{~m}^{-2}\right)$, the radioactivity deposition at time zero.

The re-suspension factor concept is very useful in radioprotection in order to estimate the inhalation of radionuclides re-suspended from contaminated surfaces when direct atmospheric measurements are lacking or difficult to perform. However, the choice of the proper values of $K$ is usually not a simple task, being quite site-specific and related to the meteorological, geomorphologic and environmental characteristics of the area to be studied. Moreover, several investigations showed clearly that the values of $K$ are a decreasing function of time. For that reason, $K$ values span several orders of magnitude: typical values in the range $10^{-5}-10^{-10} \mathrm{~m}^{-1}$ are reported in literature for different environmental conditions and time elapsed since the deposition event. The current available models for the re-suspension factor are based on empirical formulas whose parameters are highly site dependent and cannot easily be related to some physical quantity.

In this paper a simple physical model for the re-suspension factor is proposed and tested with available environmental radioactivity
\end{abstract}

This is an Open Access article distributed under the terms of the Creative Commons Attribution License 2.0, which permits unrestricted use, distribution, and reproduction in any medium, provided the original work is properly cited. 
data $\left({ }^{137} \mathrm{Cs}\right)$, collected since 1986 (Chernobyl fallout). The new model not only allows a satisfactory description of the experimental data like even the current empirical models do, but it is also able to connect the $K$ values to quantities with a physical meaning (such as, for example a diffusion-dispersion coefficient) and that are related to processes underlying resuspension.

\section{Introduction}

The atmospheric re-suspension of radionuclides is a well known phenomenon that consists in the re-injection into the atmosphere of previously deposited radioactivity. The process is driven by the action of wind on surfaces and can act as an additional source of radiation exposure by inhalation, after the deposition has finished.

In order to evaluate such exposure was introduced a parameter, the resuspension factor $K$, defined as the ratio of the volumetric air concentration $\left.C_{a}(\mathrm{~Bq} \mathrm{~m})^{-3}\right)$ to the initial soil deposition $I_{0}\left(\mathrm{~Bq} \mathrm{~m}^{-2}\right)$ and is generally considered a time depending function:

$$
K(t)=\frac{C_{a}(t)}{I_{0}} \quad\left(\mathrm{~m}^{-1}\right) .
$$

In this way the simple knowledge of the values of $K$ makes it possible to estimate the volumetric air concentration from the deposition data, usually more easily available than the actual values of concentration.

The re-suspension factor is thus widely used in all circumstances when volumetric air concentration data are needed and no direct measurements are possible. However, the choice of the proper values of $K$ is usually not a simple task, being quite site-specific and related to the meteorological, geomorphologic and environmental characteristics of the area to be studied. Moreover, several investigations showed clearly that the values of $K$ are a decreasing function of time. For that reason, $K$ values span several orders of magnitude: typical values in the range $10^{-5}-10^{-10} \mathrm{~m}^{-1}$ are reported in literature for different environmental conditions and the different length of time after the deposition event (Sehmel, 1980, IAEA Tecnical Report Series no. 472, 2010). Models were then developed in order to help the experimentalist in the choice the re-suspension values.

\section{The available models}

The re-suspension factor is a parameter that holds great importance not only from the radioprotection point of view but also for many environmental and 
radioecological studies: the migration of radionuclides across the different environmental compartments can be studied using the re-suspension factor $K$ as a useful tool. Therefore, several models for the re-suspension factor were proposed and tested in the last years using the Chernobyl accident data; in fact the widespread contamination of large areas of Europe allowed, especially during the first years after the accident, the measurements of airborne radionuclides concentration (Plutonium and Cesium-137, in particular), in very different environmental conditions.

These researches led to the formulation and testing of some empirical models, commonly used for the prediction of time evolution of the volumetric air concentration $C_{a}(t)$ in the years following a fallout event. A detailed discussion of these models can be found in the BIOMOVS II final report (Garger E.K., 1999).

The recent (2010) IAEA publication no. 472 suggested the use of three models, corresponding to three different environmental conditions, such as: a) rural conditions; b) urban conditions; c) arid and desert condition.

For rural conditions the Garland model, which obtained the best scores in the IAEA BIOMOVS II intercomparison, is proposed. It consist of a simple time decreasing relationship defined as follows:

$$
K(t)=\frac{K(0)}{t},
$$

where $K(0)=1.2 \cdot 10^{-6}$ days $\cdot \mathrm{m}^{-1}$, the time $t$ is expressed in days and the formula is valid for $t>1$ day.

For urban environment the Linsley model, consisting in an exponential decreasing function and a constant asymptotic value, is suggested:

$$
K(t)=K(0) \cdot e^{-0.01 \cdot t}+10^{-9} \mathrm{~m}^{-1},
$$

where $K(0)=10^{-6} \mathrm{~m}^{-1}$ and the time $t$ is expressed in days.

For arid and desert conditions, where re-suspension is generally more effective, the Anspaugh model is recommended:

$$
K(t)=K(0) \cdot e^{-0.15 \sqrt{t}}+10^{-9} \mathrm{~m}^{-1}
$$

with $K(0)=10^{-6} \mathrm{~m}^{-1}$.

More complicated models, based on a modification and/or a combination of the above mathematical expressions where also proposed and tested by other authors, in order to find a better agreement with local experimental data. However no significant improvements in the capability of prediction was achieved. In general, the intercomparison exercises performed in the 
past years showed that the major source of uncertainty for all models is the choice of the initial conditions, i.e. the $K(0)$ values, rather than the differences in the mathematical form of the expressions. The experimentally available data for $K(0)$ generally range between $10^{-5}$ and $10^{-6} \mathrm{~m}^{-1}$, in the first days or months after the fallout event, and are highly site specific.

All these empirical models provide quite good results for some specific situations, but the lack of knowledge of the underlying physical processes limits the possibility of generalizing, in an easy way, the results obtained in a given site to others locations, with different environmental characteristics.

From the theoretical point of view, many researchers made the assumption that the relative decrease with time of $K$ is constant, thus explaining the exponential behaviour of most of the current models. However, this would mean that the radioactivity available during the re-suspension processes reduces at a constant rate, an assumption that can hardly be considered true, especially in the mid-long term period. On the other hand, some experimental data show clearly a deviation from a simple exponential behaviour, being better described by hyperpolic time functions (see, for example, the Garland model) or by the sum of exponential functions.

It is thus clear that, at the moment, none of these current models has broad prediction capabilities (both in time and space) and can be used in different environmental conditions without an ad hoc adjustement of the fitting parameters. Moreover, it has widely been recognized that this relatively poor prediction capabilities reflects a poor understanding of the basic physical mechanism underlying re-suspension. Therefore, more researches are needed in order to find a better description of such phenomenon.

Y. Hatano and N. Hatano proposed an interesting theoretical model, very different from those described above, in 2003. This model, based on the observation of the fractal behaviour of the time series of the atmospheric activity concentration measured around Chernobyl some years after the accident, deduces an inverse time dependence of the type $K(t) \sim t^{-4 / 3}$, that fits quite well with the available experimental data. However, in spite of its mathematical brightness and its sound agreement with some experimental observations, it provides no simple connection with the physical quantities usually involved in the description of re-suspension phenomena.

\section{The new proposed model}

In this section we try to sketch a simple theory of re-suspension starting from the concept of the re-suspension rate. The re-suspension rate is defined as 
the ratio of the radioactive particle flow density above the contaminated soil $\phi_{s}\left(\mathrm{~Bq} \mathrm{~m}^{-2} \cdot \mathrm{s}^{-1}\right)$ and the initial soil deposition $I_{0}\left(\mathrm{~Bq} \mathrm{~m}^{-2}\right)$ :

$$
\Lambda(t)=\frac{\phi_{s}(t)}{I_{0}} \quad\left(\mathrm{~s}^{-1}\right) .
$$

The physical meaning of this quantity is the probability per unit time of an atom deposited on the ground surface to be re-suspended from soil into atmosphere. It depends on a number of parameters and is the outcome of many different processes (surface creep, saltation, suspension) that are highly affected by meteorological (wind and rain) and environmental conditions (type of surface). However, it should be expected that, on a yearly basis, this quantity keeps itself constant.

If this assumption is valid, the average flow $\phi_{s}\left(\mathrm{~Bq} \mathrm{~m}^{-2} \cdot \mathrm{s}^{-1}\right)$ can be expressed as follows:

$$
\phi_{s}(t)=c_{s}(t) \cdot \rho \cdot \Delta z \cdot \Lambda,
$$

where $c_{s}$ is the mass activity concentration in the soil surface $\left(\mathrm{Bq} \mathrm{kg}^{-1}\right), \rho$ $\left(\mathrm{kg} \mathrm{m}^{-3}\right)$ is the surface soil density and $\Delta z(\mathrm{~m})$ is thickness of the surface soil layer available for re-suspension. All these quantities, but $c_{s}$, evaluated as yearly averages, can be considered constant in time. In fact, the losses due to erosion and migration to depth of the deposited radioactivity, reduce progressively the radionuclide concentrations of the surface soil layers, thus decreasing the $c_{s}$ values. So, the time evolution of the flow $\phi_{s}(t)$ is essentially driven by the time evolution of $c_{s}(t)$.

The evaluation of $c_{s}(t)$ can be obtained from models describing the vertical migration of the radioactivity in soils. In fact, these models allow the calculation of a function $f(z, t)$ that gives the mass activity concentration at any time $t$ and at any given depth $z$. Therefore, if we consider $c_{s}(t)$ as the average value of the mass activity concentration in the surface soil layer $\Delta z$ available for re-suspension, we can write:

$$
c_{s}(t)=\frac{1}{\Delta z} \cdot \int_{0}^{\Delta z} f(z, t) \cdot \mathrm{d} z .
$$

The values of $c_{s}(t)$ at any given time can thus be calculated from the function $f(z, t)$, whose shape can be theoretically predicted assuming that the migration processes are described by the convection-dispersion equation (Konshin O.V., 1992; Kirchner G., 1998; Bossew P. and Kirchner G., 2003). If this is the case, the function $f(z, t)$ has a form like the following:

$$
f(z, t)=\frac{I_{0}}{\rho \cdot 2 \cdot \sqrt{\pi \cdot D \cdot t}} \cdot e^{-\frac{(z-v \cdot t)^{2}}{4 \cdot D \cdot t}}
$$


where $I_{0}$ is the initial soil deposition, $D$ is the dispersion coefficient and $v$ is the convection velocity. As the thickness of the re-suspended soil is very thin, the function $f(z, t)$ can be expanded at the first order, $f(z, t) \approx$ $f(0, t)+f^{\prime}(0, t) \cdot \Delta z$. Therefore, the integral (3) can easily be calculated, leading to the following expression:

$$
c_{s}(t)=\frac{\left[1+\frac{v \cdot \Delta z}{2 \cdot D}\right] \cdot I_{0}}{\rho \cdot 2 \cdot \sqrt{\pi \cdot D \cdot t}} \cdot e^{-\frac{v^{2} \cdot t}{4 D}} .
$$

Substituting eq. (5) into eq. (2), the average flow $\phi_{s}$ of the re-suspended material can thus be expressed as a function of the migration parameters $D, v$, as well as the thickness $\Delta z$ of the re-suspended soil.

If we make as last assumption that the deposition equals the resuspension, i.e. that the average deposition flow, defined as $\phi_{d e p}=C_{a} \cdot v_{d}$, where $v_{d}$ is the mean deposition velocity, equals $\phi_{s}$, taking into account the definition of the re-suspension factor $K(t)$ (eq. (1)), we can finally obtain:

$$
K(t)=\frac{\left[1+\frac{v \cdot \Delta z}{2 \cdot D}\right] \cdot \Delta z \cdot \Lambda}{2 \cdot \sqrt{\pi \cdot D \cdot t} \cdot v_{d}} \cdot e^{-\frac{v^{2} \cdot t}{4 D}}
$$

This is the general expression of the re-suspension factor $K(t)$, valid for any $t>0$. For $t=0$, the calculation of $K(0)$ is performed in a similar way, where in this case the $c_{s}(0)$ is still calculated from eq. (3) but that the function $f(z, t)$ under the integral approaches to a Dirac function as $t \rightarrow 0$. Therefore, we have:

$$
K(0)=\frac{\Lambda}{v_{d}} .
$$

\section{Experimental test of the model}

An experimental verification of the proposed model was performed using experimental data gathered in the period ranging from 1988 to 2007 in Ivrea, a small town of Piemonte, close to the Western Alps Ridge, in North-West Italy. In this area a considerable amount of radioactivity was deposited on the ground the days after the Chernobyl accident (from 30 April 1986 to 6 May 1986), especially due to the scavenging of the radioactive cloud by heavy precipitation events (Capra et al., 1988). Previous studies gave a detailed picture of the deposition pattern of ${ }^{137} \mathrm{Cs}$ and allowed the evaluation of the "zero point" deposition $\left(I_{0}\right)$ referred to the year 1986 in the whole 
Piemonte (Facchinelli et al., 1998, 2002). In this area the best estimation of the mean deposition value of ${ }^{137} \mathrm{Cs}$ at time zero (1 ${ }^{\text {th }}$ May 1986) was $I_{0}=36000 \mathrm{~Bq} \mathrm{~m}^{-2}$.

Starting from 1988, a time series of the re-suspension factor was then deduced evaluating $C_{a}$, the monthly averaged atmospheric activity concentration of ${ }^{137} \mathrm{Cs}$, from high purity germanium (HPGe) $\gamma$ spectrometry fallout measurements, made in the context of the national radioactivity monitoring network (Magnoni et al., 2007). The global fallout $F$, including wet and dry deposition, expressed in $\mathrm{Bq} \mathrm{m}^{-2}$, is a measure of the total radioactivity deposited on the ground: it includes a contribution coming from the higher layer of the atmosphere, as well as re-suspension. At present days the fallout is largely dominated by re-suspension. The fallout samples, monthly collected in a $4 \mathrm{~m}^{2}$ wide stainless steel tank placed on the roof of a building, reduced to dryness by evaporation and lyophilisation, were then put in jars and counted with HPGe $\gamma$-spectrometry detectors. The monthly averaged atmospheric activity concentration $C_{a}$ was then calculated as follows:

$$
C_{a}=\frac{F}{v_{d} \cdot \tau},
$$

where $F$ is the experimental value of the fallout measurements, $v_{d}$ is the mean deposition velocity of the deposited particulate and $\tau$ is the collection time of the fallout sample ( 1 month).

The values obtained for $C_{a}$ were always very low, typically ranging from $10^{-5}$ to $10^{-6} \mathrm{~Bq} \mathrm{~m}^{-3}$, and generally showed a decreasing trend with time. From these data, by the definition of the re-suspension factor (eq. (1)) the experimental values of $K$ can finally be calculated.

A more direct evaluation of $K$ would need a direct measurement of $C_{a}$ that, at present times, is very difficult, because of the very low values of ${ }^{137} \mathrm{Cs}$ air activity concentration that requires the sampling of large volumes of air. However, in order to test the reliability of the method used for the evaluation of the time series of $K$, a single $\gamma$-spectrometric measurement of $C_{a}$ was performed packing together and counting with an HPGe detector all the paper filters collected during one year (from August 2006 to July 2007). In this way it was possible to attain a sensitive measurement corresponding to a total sampled air volume of $45555 \mathrm{~m}^{3}$. The result was a mean activity concentration of $0.6 \pm 0.2 \mu \mathrm{Bq} \mathrm{m}^{-3}$, a value that is in quite good agreement with those obtained from the fallout data in the corresponding period.

Before testing the model with these experimental data, a brief discussion is needed, in order to make a correct choice of the physical parameters in eq. (6). Let's first discuss the soil migration parameters, $v$ and 
$D$, that appear in the solution of the convection-dispersion eq. (4). These quantities are related to the soil properties and are therefore site-specific. The evaluation of the values of $v$ and $D$ for the Ivrea area was performed in previous works where the downward migration of ${ }^{137} \mathrm{Cs}$ in undisturbed soils was studied analyzing the shape of ${ }^{137} \mathrm{Cs}$ concentration profiles gathered in this area from 1999 to 2006. Fitting the experimental data with the convection-diffusion model, we obtained as average values $v=0.112 \mathrm{~cm} \mathrm{yr}^{-1}$ and $D=0.037 \mathrm{~cm}^{2} \mathrm{yr}^{-1}$ (Magnoni et al., 2005), consistent with those found elsewhere, in similar environmental conditions (Bossew and Kirchner, 2003).

The other parameters to be defined are the mean deposition velocity $v_{d}$, the thickness $\Delta z$ of the re-suspended soil and the re-suspension rate $\Lambda$. While for $v_{d}$ we can take the value previously used for the determination of $C_{a}\left(v_{d}=0.18 \mathrm{~cm} \mathrm{~s}^{-1}\right)$, the thickness $\Delta z$ and the re-suspension rate $\Lambda$ can be considered as the free parameters of the model. However, in order to give the order of magnitude of these parameters, some heuristic considerations about these quantities can be made. In fact, if we assume that average height $h$ of the atmospheric mixing layer is about $1000 \mathrm{~m}$, a mean atmospheric deposition rate can be estimated as the ratio of $v_{d}$ and $h$. This ratio, because of the assumption of the equivalence between eposition and re-suspension, is nothing else but the re-suspension rate $\Lambda$ itself: we can thus obtain $\Lambda \approx$ $1.8 \cdot 10^{-6} \mathrm{~s}^{-1}$. The value of the thickness $\Delta z$ can now be estimated by the experimental data of the mass deposited in the fallout collection apparatus.

In table 1 are shown the monthly deposition data (particulate weight, in grams) and monthly mass flux $\left(\mathrm{g} \mathrm{cm}^{-2} \cdot \mathrm{s}^{-1}\right)$ referred to the period from January 2008 to March 2010.

If we take the monthly average mass flux reported in table $1\left(F_{\text {mass }}=\right.$ $\left.1.4 \cdot 10^{-10} \mathrm{~g} / \mathrm{cm}^{2} \cdot \mathrm{s}\right)$ as representative of the mean deposition rate at our sampling site, we can compute:

$$
\Delta z=\frac{F_{\text {mass }}}{\rho \cdot \Lambda}
$$

and we obtain the value $\Delta z \approx 55 \mathrm{~nm}$, a very tin layer. All the parameters in the eq. (6) are known and it is now possible to calculate the re-suspension factor $K(t)$ at any given time $t$.

Equation (9) tells also us that, given the above assumption, $\Delta z$ and $\Lambda$ are inversely correlated. Therefore, eq. (6) can put in the following form:

$$
K(t)=\frac{\left[1+\frac{v \cdot \Delta z}{2 \cdot D}\right] \cdot \frac{F_{\text {mass }}}{\rho}}{2 \cdot \sqrt{\pi \cdot D \cdot t} \cdot v_{d}} \cdot e^{-\frac{v^{2} \cdot t}{4 D}}
$$


Table 1.

\begin{tabular}{|c|c|c|}
\hline $\begin{array}{l}\text { Time of } \\
\text { sampling }\end{array}$ & $\begin{array}{c}\text { Monthly deposited particulate } \\
\text { (dry weight, grams) }\end{array}$ & $\begin{array}{c}\text { Monthly mass flux }-F_{\text {mass }} \\
\left(\mathrm{g} \mathrm{cm}^{-2} \cdot \mathrm{s}^{-1}\right)\end{array}$ \\
\hline January 2007 & 16.33 & $1.57 \cdot 10^{-10}$ \\
\hline February 2007 & 14.80 & $1.43 \cdot 10^{-10}$ \\
\hline March 2007 & 14.42 & $1.39 \cdot 10^{-10}$ \\
\hline April 2007 & 16.81 & $1.62 \cdot 10^{-10}$ \\
\hline May 2007 & 25.28 & $2.44 \cdot 10^{-10}$ \\
\hline June 2007 & 17.22 & $1.66 \cdot 10^{-10}$ \\
\hline July 2007 & 17.78 & $1.71 \cdot 10^{-10}$ \\
\hline August 2007 & 19.05 & $1.84 \cdot 10^{-10}$ \\
\hline September 2007 & 19.85 & $1.91 \cdot 10^{-10}$ \\
\hline October 2007 & 14.53 & $1.40 \cdot 10^{-10}$ \\
\hline November 2007 & 15.14 & $1.46 \cdot 10^{-10}$ \\
\hline December 2007 & 15.67 & $1.51 \cdot 10^{-10}$ \\
\hline January 2008 & 5.62 & $5.42 \cdot 10^{-11}$ \\
\hline February 2008 & 5.14 & $4.96 \cdot 10^{-11}$ \\
\hline March 2008 & 6.18 & $5.96 \cdot 10^{-11}$ \\
\hline April 2008 & 10.67 & $1.03 \cdot 10^{-10}$ \\
\hline May 2008 & 21.51 & $2.07 \cdot 10^{-10}$ \\
\hline June 2008 & 13.94 & $1.34 \cdot 10^{-10}$ \\
\hline July 2008 & 12.20 & $1.18 \cdot 10^{-10}$ \\
\hline August 2008 & 6.63 & $6.39 \cdot 10^{-11}$ \\
\hline September 2008 & 12.44 & $1.20 \cdot 10^{-10}$ \\
\hline October 2008 & 6.29 & $6.07 \cdot 10^{-11}$ \\
\hline November 2008 & 12.00 & $1.16 \cdot 10^{-10}$ \\
\hline December 2008 & 8.04 & $7.75 \cdot 10^{-11}$ \\
\hline January 2009 & 11.75 & $1.13 \cdot 10^{-10}$ \\
\hline February 2009 & 14.09 & $1.36 \cdot 10^{-10}$ \\
\hline March 2009 & 27.8 & $2.68 \cdot 10^{-10}$ \\
\hline April 2009 & 30.75 & $2.97 \cdot 10^{-10}$ \\
\hline May 2009 & 26.42 & $2.55 \cdot 10^{-10}$ \\
\hline
\end{tabular}


Table 1. Continued.

\begin{tabular}{|c|c|c|}
\hline $\begin{array}{c}\text { Time of } \\
\text { sampling }\end{array}$ & $\begin{array}{c}\text { Monthly deposited particulate } \\
\text { (dry weight, grams) }\end{array}$ & $\begin{array}{c}\text { Monthly mass flux }-F_{\text {mass }} \\
\left(\mathrm{g} \mathrm{cm}^{-2} \cdot \mathrm{s}^{-1}\right)\end{array}$ \\
\hline June 2009 & 23.63 & $2.28 \cdot 10^{-10}$ \\
\hline July 2009 & 26.35 & $2.54 \cdot 10^{-10}$ \\
\hline August 2009 & 21.22 & $2.05 \cdot 10^{-10}$ \\
\hline September 2009 & 16.26 & $1.57 \cdot 10^{-10}$ \\
\hline October 2009 & 5.07 & $4.89 \cdot 10^{-11}$ \\
\hline November 2009 & 3.96 & $3.82 \cdot 10^{-11}$ \\
\hline December 2009 & 5.12 & $4.94 \cdot 10^{-11}$ \\
\hline January 2010 & 4.65 & $5.48 \cdot 10^{-11}$ \\
\hline February 2010 & 5.32 & $1.28 \cdot 10^{-11}$ \\
\hline March 2010 & 13.29 & $(\mathbf{1 . 4} \pm \mathbf{0 . 7}) \cdot \mathbf{1 0}$ \\
\hline $\begin{array}{c}\text { Monthly } \\
\text { Average }\end{array}$ & $\mathbf{1 4} \mathbf{7}$ & 5.13 \\
\hline
\end{tabular}

where the explicit dependence on the re-suspension rate $\Lambda$ is eliminated and appears $F_{\text {mass }}$, an experimentally evaluated quantity. Equation (10) can thus be used for testing the new model with experimental data.

In fig. 1 the new model predictions are compared with those obtained with some available models. It can be seen that the new model predictions fit quite well with the experimental data. In particular the agreement of our model with the experimental data seems significantly better than that achievable with the exponential models that fit well only on a limited subset of the whole data.

\section{Conclusions}

The test of the new re-suspension factor model showed a quite good agreement with available experimental data. The model fits clearly better than the single exponential models. Our model seems also to describe better a long-term behaviour that, in this case, seems to be overestimated and underestimated, respectively, in the Garland and Hatano models. Moreover, the new model not only gives a more satisfactory description of the experimental data than the current empirical models do, but it is also able 


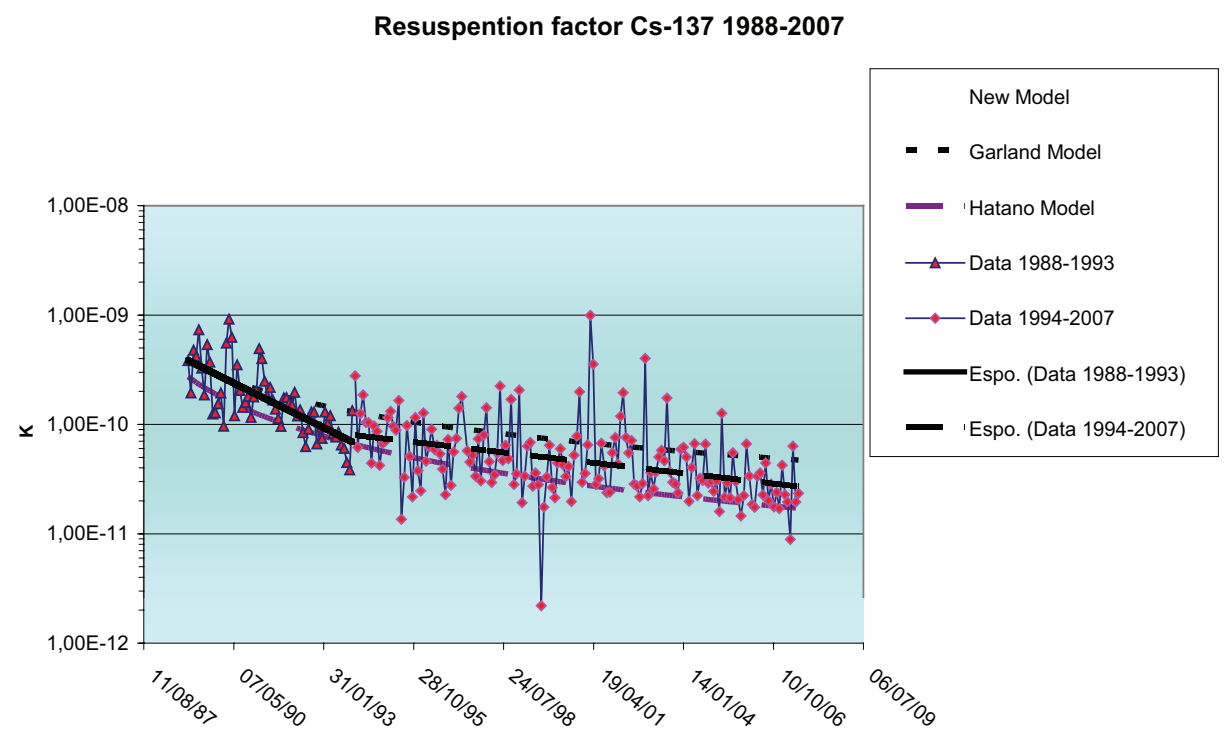

Figure 1. Model test and comparison with some available models.

to connect the $K$ values to physical parameters (such as, the diffusiondispersion coefficients, the re-suspension rate, the thickness of soil available for re-suspension) that are strongly related to the processes underlying re-suspension.

However, new tests of the model with experimental data gathered elsewhere are needed in order to verify a wider applicability of this approach also in different environmental conditions.

\section{References}

[1] Bossew P. and Kirchner G., "Modeling the vertical distribution of radionuclides in soils. Part 1: The convection-dispersion equation revisited", Journal of Envirnonmental Radioactivity (2003).

[2] Capra D. et al., "The Chernobyl accident: soil deposition of radionuclides in Po Plain and Alpine Valleys", AcquaESAria, 3, 305-319 (1988).

[3] Facchinelli A. and Magnoni M., "Radioattività ambientale e radiocontaminazione dei suoli piemontesi", Collana Ambiente no. 14 - Regione Piemonte (1998) in Italian. 
[4] Facchinelli A. et al., "Cs-137 contamination from Chernobyl of soils in Piemonte: spatial distribution and deposition model", Water Air, and Soil Pollution, 134, 341-352 (2002).

[5] Garger E.K. et al., "Test of existing mathematical models for atmospheric resuspension of radionuclides", Journal of Envirnonmental Radioactivity, 42, 157-175 (1999).

[6] Hatano Y. and Hatano N., "Formula for the resuspention factor and estimation of the date of surface contamination", Atmospheric Environment, 37, 3475-3480 (2003).

[7] IAEA, "Handbook of Parameter Values for the Prediction of Radionuclide Transfer in Terrestrial and Freshwater Environments", Technical Report Series no. 472 (2010).

[8] Konshin O.V., "Applicability of the convection-diffusion mechanism for modelling migration of ${ }^{137} \mathrm{Cs}$ and ${ }^{90} \mathrm{Sr}$ in the soil", Health Physics, 63, 291-300 (1992).

[9] Konshin O.V., "Mathematical model of ${ }^{137} \mathrm{Cs}$ migration in soil: analysis of observations following the Chernobyl accident", Health Physics, 63, 301-306 (1992).

[10] Kirchner G., "Applicability of compartment models for simulating the transport in soils", Journal of Envirnonmental Radioactivity, 38, 339352 (1998).

[11] Magnoni M., "Stima dell'evoluzione temporale della risospensione per mezzo di misure di fallout", Proceedings of AIRP National Congress, Vasto, 1-3 October 2007 (in Italian).

[12] Magnoni M. et al., "La migrazione del Cs-137 nei suoli del Piemonte: dati sperimentali ed effetto della distribuzione verticale sui livelli di dose da irraggiamento $\gamma^{\prime \prime}$, Proceedings of the XXXIII Congresso Nazionale AIRP di Radioprotezione, Torino, 15-17 September 2005 (in Italian).

[13] Sehmel G.A., "Particle resuspension: a review", Env. Int., 4, 107-127 (1980). 